\title{
Congenital Cholesteatoma of Mastoid Temporal Bone and Posterior Cranial Fossa Treated with Transmastoid Marsupialization
}

\author{
Chung Man Sung, Hyung Chae Yang, Yong Beom Cho, and Chul Ho Jang \\ Department of Otolaryngology-Head and Neck Surgery, Chonnam National University Medical School and \\ Chonnam National University Hospital, Gwangju, Korea
}

\section{유양동과 후두개와에 위치하는 선천성 진주종의 경유양동 조대술을 통한 치료}

성충만 · 양형채 · 조용범 · 장철호

전남대학교 의과대학 전남대학교병원 이비인후과학교실

\author{
Received April 5, 2017 \\ Revised May 31, 2017 \\ Accepted June 10, 2017 \\ Address for correspondence \\ Chul Ho Jang, MD, PhD \\ Department of Otolaryngology- \\ Head and Neck Surgery, \\ Chonnam National University \\ Medical School and \\ Chonnam National University \\ Hospital, 42 Jebong-ro, Dong-gu, \\ Gwangju 61469, Korea \\ Tel +82-62-220-6776 \\ Fax +82-62-228-7743 \\ E-mail chulsavio@hanmail.net
}

A congenital cholesteatoma is a benign mass formed from the keratinizing stratified squamous epithelium. It usually occurs in young children's anterosuperior part of the middle ear. A congenital cholesteatoma which originates from mastoid temporal bone or expands to posterior cranial fossa is rare. Standard treatment of an intracranial cholesteatoma is surgical removal with craniotomy. A 69-year-old woman was diagnosed with a congenital cholesteatoma of mastoid temporal bone that expanded to the posterior cranial fossa, which was successfully treated with transmastoid marsupialization without craniotomy. This is a first documented case of a congenital cholesteatoma of mastoid temporal bone that expanded to posterior cranial fossa, which was successfully treated with transmastoid marsupialization without craniotomy.

Korean J Otorhinolaryngol-Head Neck Surg 2018;61(12):710-3

Key Words Cholesteatoma $\cdot$ Epidermoid tumor $\cdot$ Occipital bone $\cdot$ Posterior cranial fossa Temporal bone.

\section{Introduction}

The term congenital cholesteatoma is most commonly used to describe tumors that occur in the middle ear. Some authors have used a broader definition of congenital cholesteatoma to include all epidermoid cysts in the central nervous system. ${ }^{1)}$ Although there is no histopathological difference between congenital cholesteatoma and epidermoid cysts, ${ }^{2)}$ they do differ radiologically and clinically. ${ }^{3-5)}$ Warren, et al. ${ }^{5)}$ reported that the clinical presentation of congenital cholesteatoma originated from mastoid. We also encoun-

This is an Open Access article distributed under the terms of the Creative Commons Attribution Non-Commercial License (https://creativecommons.org/licenses/by-nc/4.0) which permits unrestricted non-commercial use, distribution, and reproduction in any medium, provided the original work is properly cited. tered a rare case of isolated mastoid congenital cholesteatoma expanding to the occipital bone. Although there may be controversy about whether the mass is a congenital cholesteatoma or an epidermoid cyst, we performed a successful treatment via transmastoid approach without craniotomy. So, we report our experience and provide a review of the literature regarding congenital cholesteatoma isolated to the mastoid.

\section{Case}

The Institutional Review Board of Chonnam National University Hospital approved this study protocol (CNUHEXP-2016-332). A 69-year-old woman presented with a recent (3 days) onset of headache and dizziness. Dizziness was non- 


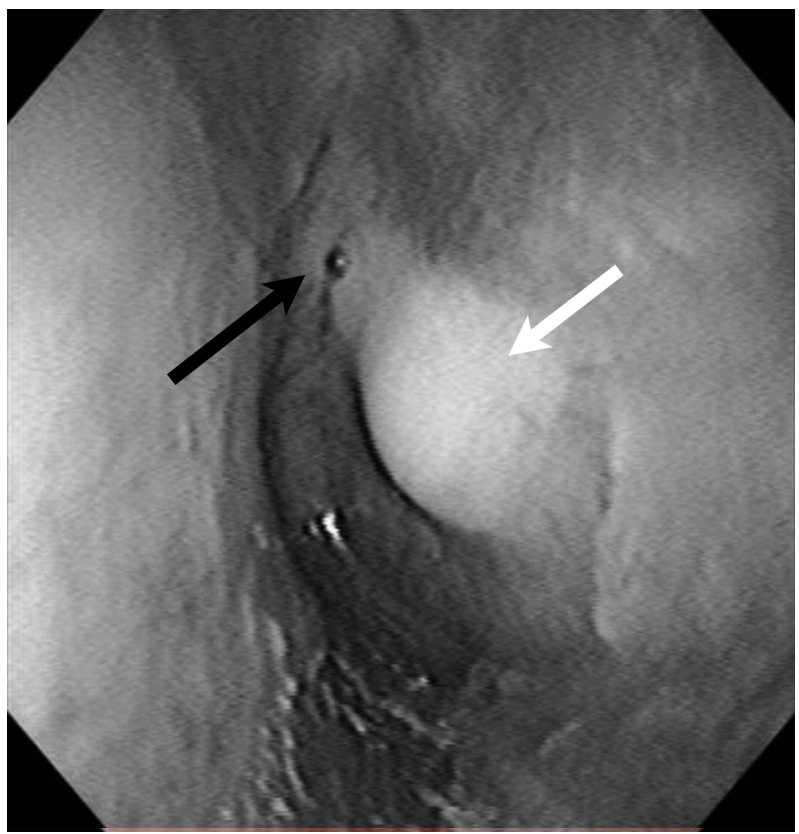

Fig. 1. Images of left ear drum. Scanty prulent discharge (black arrow) is noted and there was whitish mass-like lesion (white arrow) behind an intact ear drum. whirling type and there was no specific neurological symptom. She had a 2-months history of left-sided otorrhea that was poorly responsive to empirical treatment at a primary hospital. She had no previous history of surgery. She was misdiagnosed as congenital middle ear cholesteatoma at a primary hospital, because otoscope revealed whitish mass be"hind an intact ear drum (Fig. 1). She was referred to a tertiary hospital under a diagnosis of congenital middle ear cholesteatoma. Pure tone audiometry revealed a conductive hearing loss. The left mastoid air cell and middle ear cavity appeared soft tissue attenuation on axial views of temporal bone computed tomography (TBCT) (Fig. 2A). Coronal views of TBCT demonstrated a $4.7 \times 2.2 \mathrm{~cm}$ mass-like space-occupying lesion expanding to the posterior cranial fossa that destroyed part of mastoid, parietal, and occipital (Fig. 2B). The mass occluded the adjacent transverse sinus. It was hyperintense and mottled on T1-weighted magnetic resonance imaging (T1WI), hypointense on T2-weighted imaging (T2WI) without contrast-enhancing (Fig. 3). Conventional C-shape

Fig. 2. Computed tomographic images of left temporal bone showing soft tissue density on mastoid antrum and middle ear cavity, and eroded mastoid and posterior cranium; axial image $(A)$, coronal image $(B)$.
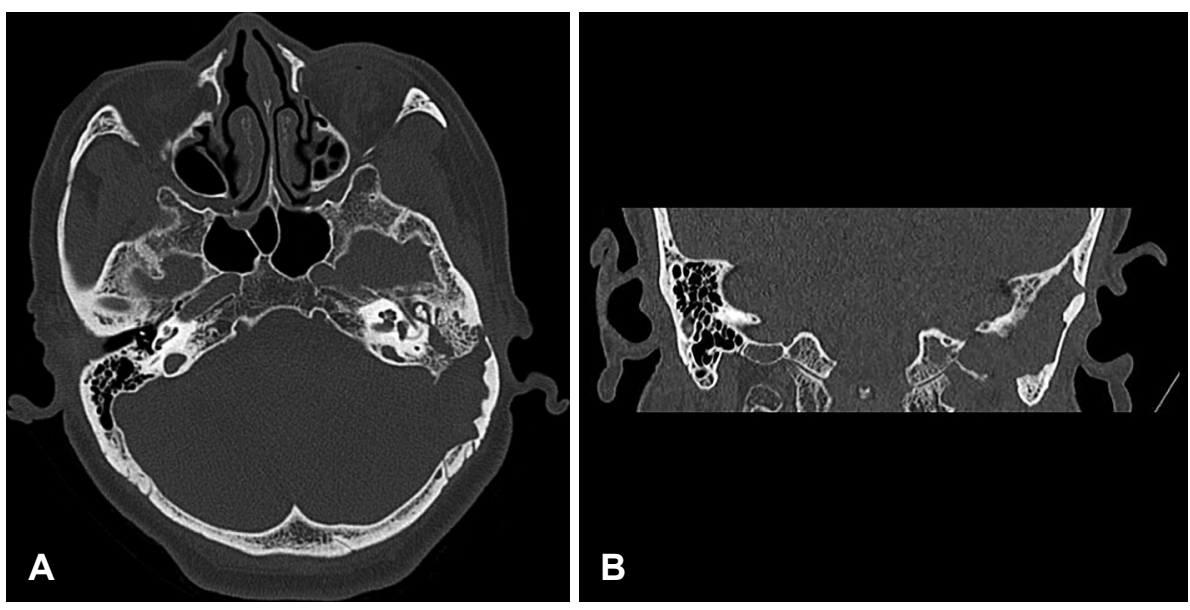

Fig. 3. MRI scan demonstrating lesion of the left posterior fossa and temporal bone; high signal intensity on T2-weighted axial MRI scan (A), T2-weighted coronal MRI scan (B).
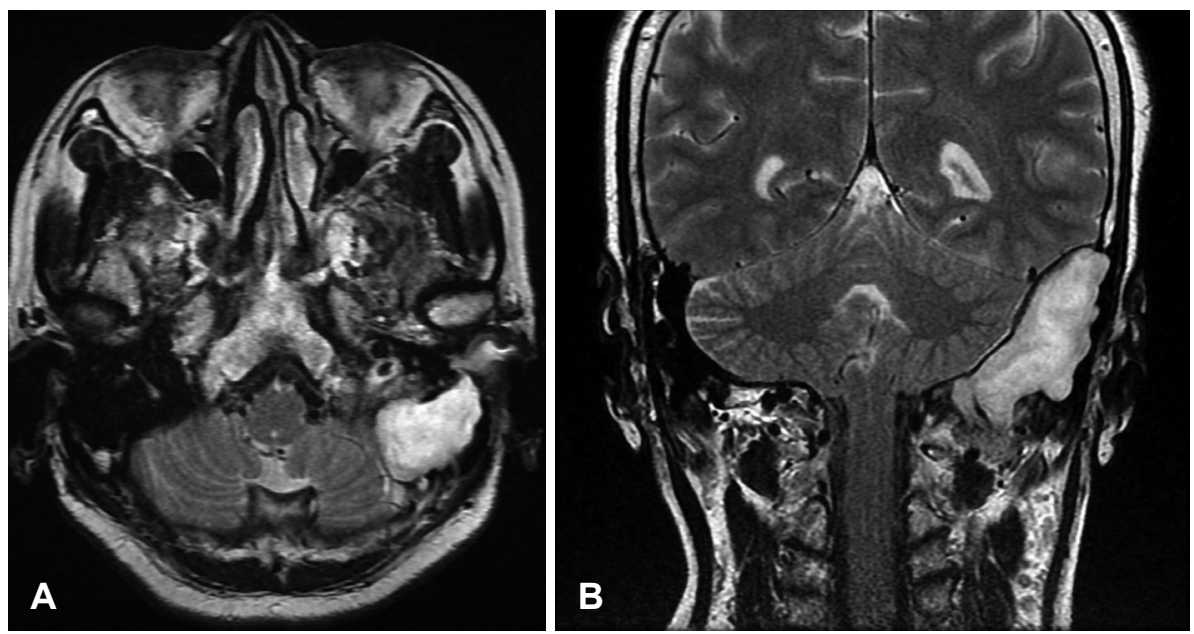
post-auricular skin incision was made for surgical intervention. Tympanomeatal flap was elevated. A defect of the mastoid cortex was observed. Pus-filled keratinous material was suctioned through the defect. However, there was only a small amount of effusion inside the middle ear and no keratinous material. In addition, the middle ear mucosa and ossicles maintained normal structure. Mastoidectomy was performed from the point of cortical destruction identified from preoperative TBCT. Mastoidectomy revealed relative healthy mastoid air cell anteriorly and intact sigmoid sinus wall. However, there was purulent discharge-filled pearly keratinous material at restrosigmoid area to posterior cranial fossa (Fig. 4). The mass was removed via transmastoid retrosigmoid approach without craniotomy. It was possible to achieve near-total excision, leaving only the adherent cholesteatoma sac lining behind, because it was tightly adhered to the dura. The exposed dura was not covered and open cavity mastoidectomy was performed without obliteration to detect changes in remnant cholesteatoma. Immediately after sur-

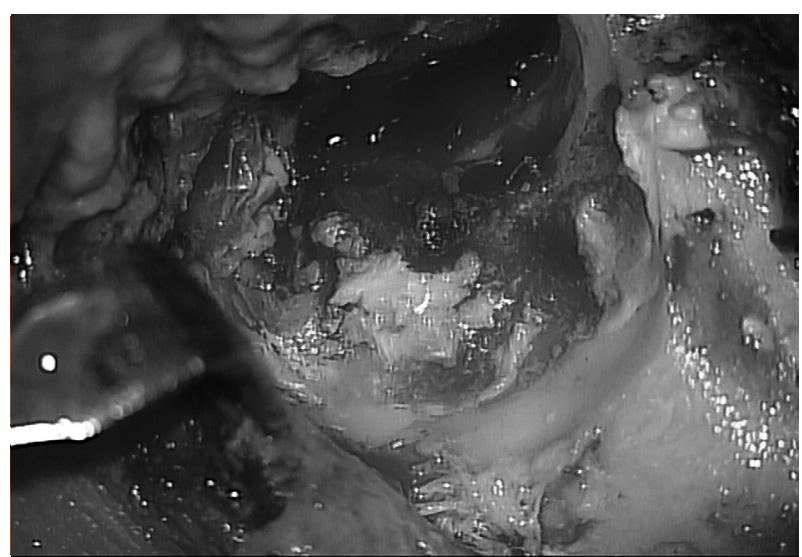

Fig. 4. There was a purulent discharge-filled pearly keratinous material at poasterior mastoid. gery, ear dressing with use of otic drop was performed frequently. At this time, partial removal of the remnant cholesteatoma using the suction was also performed. Pathologic examination of the surgical specimen disclosed considerable keratinous material and stratified squamous epithelium which were consistent with the diagnosis of cholesteatoma. Headache and hearing loss improved after surgery and, a follow-up CT imaging at 1 year post operation showed well marsupialized cavity (Fig. 5).

\section{Discussion}

It is difficult to differentiate congenital cholesteatoma from epidermoid cyst because they have similar radiologic, histopathologic and clinical features. Both of them have mass of soft tissue density, pressure erosion on adjacent bone, no contrast enhancement on CT, low signal intensity in T1WI, high signal intensity in T2WI, and no enhancement on MRI image. Pathologically, both have keratinized squamous epithelia, including keratin. ${ }^{4,6)}$ They typically present with painless mass of the scalp due to their slow growing nature. However, rarely complications including malignant change, abscess formation, hemorrhage, and intracranial mass effect do occur. ${ }^{7)}$ Some authors suggest that epidermoid cyst and cholesteatoma are the same disease entity. ${ }^{4)}$

However, congenital cholesteatoma tends to be more invasive into surrounding bones and air cells than epidermoid cyst. Congenital cholesteatoma destroys bone through osteoclastic bone resorption rather than through pressure necrosis secreting interleukin- $\alpha$, fibroblast production, collagenase, and granulocyte-macrophage colony-stimulating factor ${ }^{5)}$ Lee $^{3)}$ suggested radiologic differences between cholesteatoma and epidermoid cyst. Epidermoid cyst has a rounder, well-demar-
Fig. 5. Postoperative axial image (A) and coronal image (B) of computed tomography shows well marsupialized cavity.
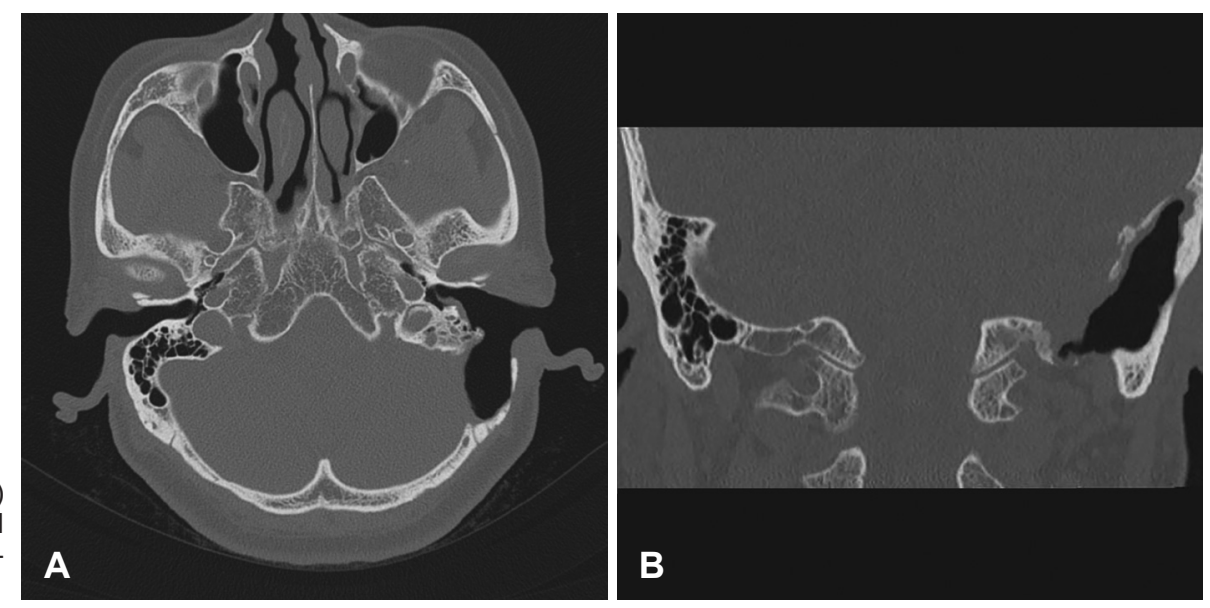
cated contour with boundary between adjacent bones clearer and smoother. Cholesteatoma mostly shows sharply marginated and expansile mass with irregular and scalloped margin and accompanied by various degrees of bony erosion. ${ }^{3)}$

Unlike usual clinical feature of epidermoid cyst, our case patient presented with intractable otorrhea. The most common symptom of an epidermoid cyst is painless swelling of scalp due to the slow growth of the tumor. When they become sizable, they may produce headache, increased intracranial pressure, seizure, on-going hemiparesis, and other local neurological signs. ${ }^{4-6)}$ However, bone resorption by cholesteatoma may cause other problems such as hearing impairment and vertigo, ${ }^{9)}$ which is another difference between cholesteatoma and epidermoid cyst.

The reported patient had two months history of otorrhea. Her ear drum was intact. However, there was whitish masslike lesion behind the ear drum on otoscopic examination (Fig. 1). CT and MRI showed that the mass expanded to the posterior cranial fossa and destroyed the temporal, parietal, and occipital bone. The mass compressed the lateral sinus (Figs. 2 and 3). Although the mass did not involve middle ear cavity, the middle ear was filled with thick yellowish discharge. Considering both radiologic and clinical feature, we concluded that this was a case of isolated mastoid congenital cholesteatoma which involving temporal, parietal, occipital bone, and posterior cranial fossa. Moreover, this mass compressed and occluded the lateral sinus and it was well demonstrated by radiologic image. To our knowledge, only one case of large intradiploic epidermoid of temporal bone which compressed lateral sinus has been reported in the literature. However the mastoid of this case was preserved from a mass. ${ }^{10)}$

Standard treatment of an intradiploic epidermoid cyst is surgical removal with complete resection. ${ }^{8)}$ However, it needs craniotomy. Lesions localized in the area of the major dural sinuses are of special concern because potential major bleeding problems may occur during surgical exploration. ${ }^{10)}$ To reduce complications from operation, keratinous materials were marsupialized and desquamated from the bone and dura mater carefully. During 30 months postoperative follow up period, there was an event of cavity problem. She developed otomycosis at postoperative 28 month. However, otomycosis was well controlled by vinegar irrigation.

This case showed the patient who presented with intractable otorrhea had a large congenital cholesteatoma that expanded to posterior cranial fossa and compressed major vessel causing epidural abscess to middle ear cavity. Even if patients only with otorrhea did not respond to medication with newly developed neurologic symptoms, imaging study should be performed. In addition, transmastoid marsupialization can be a choice for otolaryngologist in treating giant cholesteatoma that extends to post cranial fossa.

\section{Acknowledgments}

This research was supported by the Bio \& Medical Technology Development Program of National Research Foundation of Korea (NRF) funded by the Korean government MSIP (NRF-2017M3A9E8023021).

\section{REFERENCES}

1) Axon PR, Fergie N, Saeed SR, Temple RH, Ramsden RT. Petrosal cholesteatoma: management considerations for minimizing morbidity. Am J Otol 1999;20(4):505-10.

2) Constans JP, Meder JF, De Divitiis E, Donzelli R, Maiuri F. Giant intradiploic epidermoid cysts of the skull. Report of two cases. J Neurosurg 1985;62(3):445-8.

3) Lee DH. Intradiploic epidermoid cyst of the temporal bone: is it the same as or different from cholesteatoma? J Craniofac Surg 2011;22 (5):1973-5.

4) Clark MP, Pretorius PM, Beaumont D, Milford CA. Congenital cholesteatoma of occipital bone or intradiploic epidermoid cyst? One and the same disease. J Laryngol Otol 2009;123(6):673-5.

5) Warren FM, Bennett ML, Wiggins RH 3rd, Saltzman KL, Blevins KS, Shelton C, et al. Congenital cholesteatoma of the mastoid temporal bone. Laryngoscope 2007;117(8):1389-94.

6) Arana E, Latorre FF, Revert A, Menor F, Riesgo P, Liaño F, et al. Intradiploic epidermoid cysts. Neuroradiology 1996;38(4):306-11.

7) Shellenberger DL, Roehm PC, Gantz B. Large extradural epidermoid tumor of the temporal bone and posterior fossa cranium. Otol Neurotol 2006;27(7):1043-4.

8) Jaiswal AK, Mahapatra AK. Giant intradiploic epidermoid cysts of the skull. A report of eight cases. Br J Neurosurg 2000;14(3):225-8.

9) Kim MJ, Chang KH, Han GC. Large intradiploic epidermoid cyst of the temporal bone. J Int Adv Otol 2014;10(2):187-9.

10) Sadato N, Numaguchi Y, Geisler FH, Kristt DA. Extradural epidermoid cyst occluding the transverse sinus: a case report. Comput Med Imaging Graph 1991;15(2):129-32. 